\title{
EDUCATION MATTERS
}

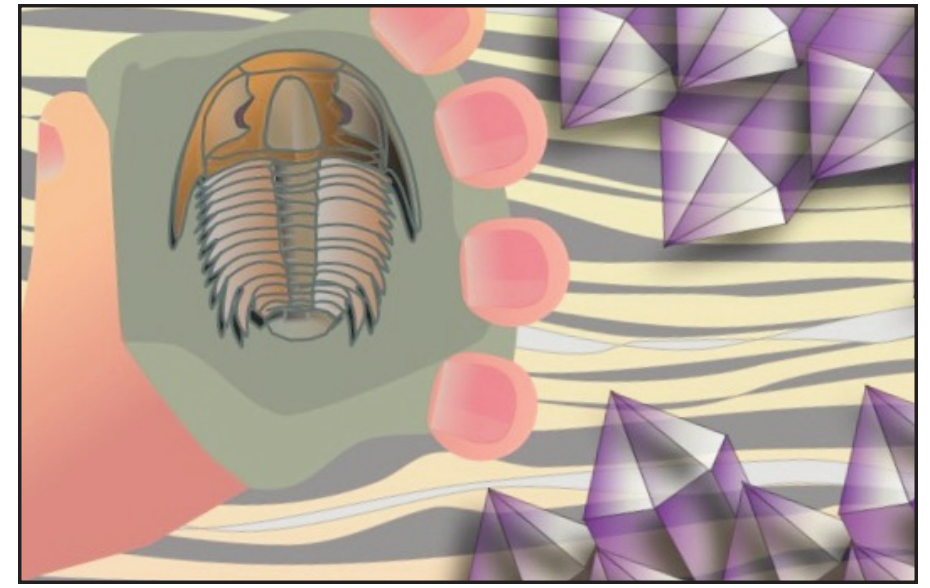

\section{The 'Rock ' $n$ ' Fossil Road Show:' An Enduring Earth Science Educational Outreach Initiative in Calgary, Alberta}

\author{
Robert B. MacNaughton, Godfrey S. Nowlan, \\ Alexander D. McCracken, and Karen M. Fallas \\ Geological Survey of Canada (Calgary) \\ Natural Resources Canada \\ 3303-33rd Street NW, Calgary, Alberta, T2L 2A7, Canada \\ E-mail: Robert.MacNaughton@canada.ca
}

\section{SUMMARY}

Since 2004, the Calgary office of the Geological Survey of Canada has been holding 'Rock 'n' Fossil Road shows' at Calgary Public Library branches, in partnership with the Alberta Science Network and the Alberta Palaeontological Society. These now-annual earth science education outreach events have given more than 3700 people of all ages the opportunity to view, examine, and learn about GSC-Calgary's collection of rocks, minerals, and fossils (including many museum quality pieces), have their own samples and collections identified by experts, and gain a better understanding of local and regional geology. This article describes what goes into organizing these events, reviews their evolution, and discusses reasons for their enduring success. The 'Road Show' approach can be viable in a range of settings and may be a good educational outreach option for research institutes with collections of interesting geological specimens and a critical mass of interested staff.

\section{RÉSUMÉ}

Depuis 2004, le bureau de Calgary de la Commission géologique du Canada tient des représentations de son spectacle itinérant "Roche et fossiles » dans les succursales de la bibliothèque publique de Calgary, en partenariat avec l'Alberta Science Network et l'Alberta Palaeontological Society. Ces activités de rayonnement en sciences de la Terre, maintenant annuels, ont déjà offert à plus de 3700 personnes de tous âges la possibilité de voir, d'examiner et d'apprendre à partir de la collection de roches, de minéraux et de fossiles de la CGC-Calgary (certaines pièces de qualité muséale), et de voir leurs propres échantillons et collections identifiés par des experts, et ainsi obtenir une meilleure compréhension de la géologie locale et régionale. Le présent article décrit les détails de l'organisation de ces événements, retrace leur évolution et revoit les raisons de leur succès durable. L'approche du "spectacle itinérant » peut être viable dans différents contextes et peut être une bonne option de sensibilisation éducative pour les instituts de recherche disposant de collections de spécimens géologiques intéressants et d'une masse critique d'employés intéressés.

Traduit par le Traducteur

\section{INTRODUCTION}

For thirteen years, the Calgary office of the Geological Survey of Canada (GSC-Calgary) has been taking science to the public by means of the 'Rock 'n' Fossil Road Show.' Each year, scientists and staff visit a branch of the Calgary Public Library (CPL) on a Saturday in mid-October with a display of more than one hundred high-quality mineral, rock, and fossil specimens, as well as maps and posters on local and regional geology. Members of the public can interact with GSC volunteers to learn about the displays, and they also can bring their own favourite geological specimens to be identified and explained. These events, held in partnership with the Alberta Science Network <http://albertasciencenetwork.ca>, the Calgary Public Library system <https://calgarylibrary.ca>, and the Alberta Palaeontological Society <http://www.albertapaleo. org $>$, annually give hundreds of people hands-on experience with minerals, rocks, and fossils, as well as face-to-face interactions with working earth scientists (Fig. 1). These events are aimed at increasing public awareness of the earth sciences, encouraging earth science literacy, and sowing the seeds of interest that may attract a future generation of earth scientists. This article is a brief account of this long term educational outreach initiative, its history, and how we make it happen. Our experience suggests that the 'Road Show' approach can be 


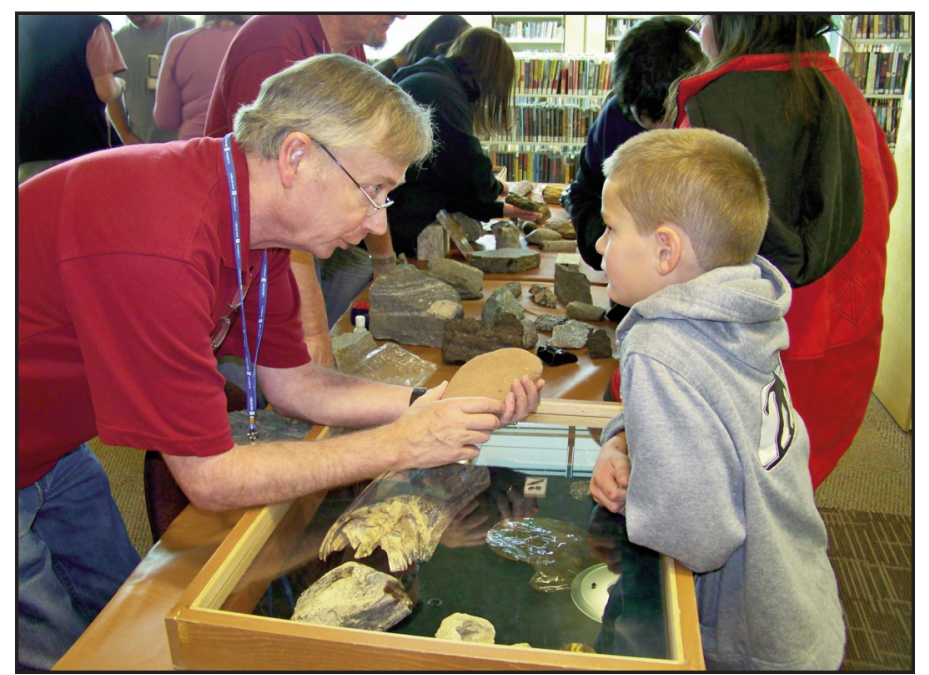

Figure 1. Interactions with earth scientists, focused on discussions of actual geological specimens, are key elements to the success of the Rock 'n' Fossil Road Show.

adapted by other research institutions interested in fun and effective public educational outreach programs.

\section{BACKGROUND}

GSC-Calgary has a long history of public educational outreach, including playing a key role in the establishment and success of the Calgary Science Network (Nowlan and Neale 2000), which is now part of the province-wide Alberta Science Network (ASN). The present Rock 'n' Fossil Road Show has its origins in the 'Pet Rock and Fossil Clinic,' an earlier collaboration of GSC-Calgary, the Calgary Science Network, and National Science and Technology Week. Beginning in 1991, the lobby of the GSC-Calgary building was opened to the public on a Saturday in October. GSC scientists (sometimes with assistance from staff of the Royal Tyrrell Museum of Palaeontology) were on hand as collectors of all ages came with their favourite pet rock and fossil specimens. As recounted by Nowlan and Neale (2000, p. 26), the 'rock docs' ensured that the clients "...were told something of the composition, age and history of their pets and, more important, shown the simple tests that would enable them to name and classify their treasures". Attendance peaked with 800 visitors in 1995 but fell rapidly thereafter for reasons that were never determined. The event was abandoned after attendance in 1997 barely surpassed 100 people. By 2000, however, there were "...calls for a post-mortem and possible resurrection or metamorphism" (Nowlan and Neale 2000, p. 26).

In the early 2000s, GSC-Calgary scientists participated in a Rock and Fossil Clinic at the Calgary Science Centre, and at least twice had an outreach presence at a family fun day called "Hullabaloo," held at Calgary's Olympic Oval. In August, 2004, planning began for a Pet Rock and Fossil Clinic, to be held at CPL's Crowfoot Library in October of that year. Although the event was promoted as a Pet Rock and Fossil Clinic, and like the earlier clinics was staffed by volunteers from GSC-Calgary and the Royal Tyrrell Museum, it also was attended by staff from SciQ, a television production company, who were filming an educational program that put a geological twist on the popular Antiques Roadshow. Rock 'n' Fossil Road Show featured earth scientists examining and explaining geological specimens that had been brought in by the public. Only one episode was produced (it aired on Access TV the following February), but the event was successful enough to suggest a new name and approach to geoscience education outreach, particularly since CPL was keen to continue hosting the event. The Pet Rock and Fossil Clinic was resurrected and metamorphosed as the Rock 'n' Fossil Road Show.

\section{HOW IT WORKS}

The Rock 'n' Fossil Road Show is organized each year by a committee of two or three people, generally with one person taking the lead and the others assisting. Early each spring, the organizers scout a library branch in Calgary to host that fall's event. We have tried to hold the events throughout the city, at as many different branches as we can. By visiting the candidate library, we can ensure that staff members at the branch are keen to host the Road Show and that the venue offers adequate space, light, and access. Choosing a venue in early spring gives plenty of time for CPL to approve the event and include it in their event listings.

Promotions for the event are handled mainly by ASN, with help from Natural Resources Canada communications staff for some events. ASN ensures that the Road Show is announced in their own newsletter and via community bulletin boards and flyers. They also publicize it to schools near the host library, and in the past have put up posters in local grocery stores, community centres, and other meeting places. CPL contributes to publicity by announcing the event in its online and printed event schedules. To further advertise the event, CPL allows us to place a glass display case full of museum-quality geological specimens in a prominent spot in the host branch, three weeks prior to the event. The event is promoted as being for all ages, and the libraries do not restrict the number of participants or require advance registration.

On the Saturday morning of the event, we arrive at the library an hour before the scheduled starting time, to ensure adequate time for setup. In addition to a wide range of highquality minerals, rocks, and fossils (Fig. 1), we also take a binocular microscope and a commercially produced 'find a fossil' kit, as well as reference books to help in identifying minerals and fossils. We take a portable backdrop on which we mount geoscience maps and outreach posters, such as Geoscape Calgary (Poulton et al. 2002; see also Turner 2013), and a large simple poster of the geologic time scale (Fig. 2). The event runs from 11:00-15:00. Afterwards, it can require up to an hour to dismantle and pack up the displays.

To aid those who may consider staging a similar event, we offer the following summary of time requirements. For keen volunteers, the Road Show event itself is a day-long commitment. Some also participate in the packing (2-3 hours the day before the event) and unpacking of samples (generally about 2 hours). The lead organizers expend roughly another 14 hours, spread among 2 or 3 people, for scouting the location, dealing with paperwork and promotions, delivering the display case, and doing wrap-up reporting after the event. 


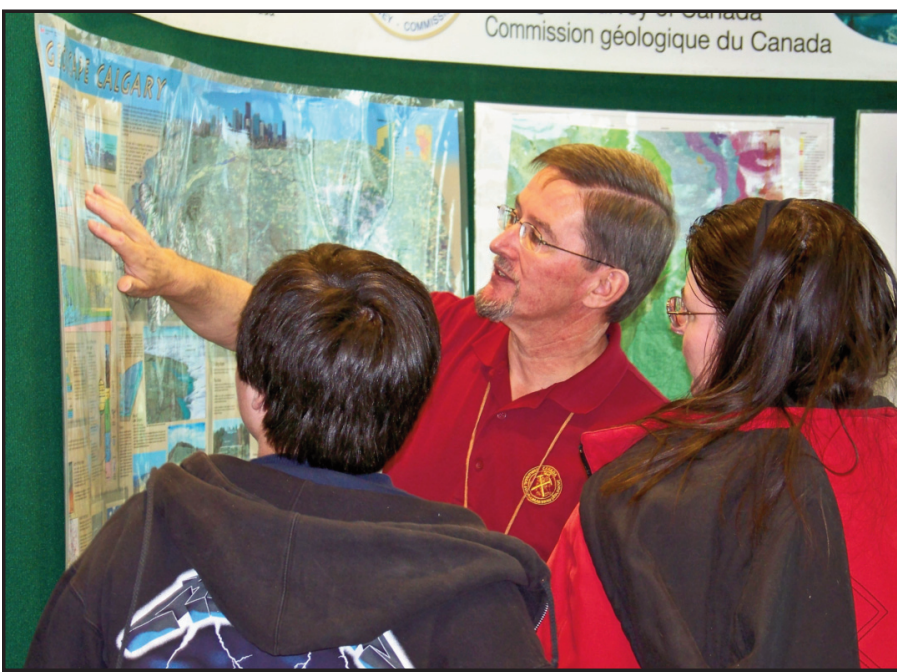

Figure 2. General interest posters, such as Geoscape Calgary (Poulton et al. 2002; Turner 2013), are an important part of the displays at each Rock 'n' Fossil Road Show.

\section{EVOLUTION OF THE ROCK 'N' FOSSIL ROAD SHOW}

Since the first event in 2004, the Rock ' $n$ ' Fossil Road Show has evolved in response to both challenges and opportunities. A major change is that the Road Show initially was held twice a year but from 2010 onward became an annual event, in response to the excessive demands that biannual Road shows had come to make on organizers and volunteers. A fall show made sense because of the event's longstanding association with National Science and Technology Week (NSTW), and also because it avoided any scheduling conflict with the Calgary Rock and Lapidary Club's annual show, which is held in the spring. In 2016, NSTW was renamed "Science Odyssey" and moved to the spring. Although we valued our role as part of NSTW, we decided to continue holding our event in the fall-not least because spring is a busy time of year for earth scientists who are preparing for summer field work.

The make-up of our volunteer contingent also has changed. After the first Road Show, early events were staffed almost entirely by Research Scientists from GSC-Calgary. As GSC research staff numbers have shrunk, we have come to rely increasingly on retirees, students, technical staff, and postdoctoral fellows to run the event. We also have been joined on occasion by administrative staff, whose lack of earth-science expertise was more than offset by their ability to interact enthusiastically with the public. A welcome addition to our volunteer ranks came during the first two years of the Road Show's history, when we began an informal partnership with the Alberta Palaeontological Society (APS). APS members have been a small and enthusiastic volunteer contingent at some events, particularly "Dino Dan" Quinsey, a fossil collector with a passion for public outreach, who has attended most events. Dan continues to bring unique, engaging, high-quality displays to virtually every Road Show. From 2011-2014, we also were joined by staff from the CanmetMATERIALS Pipelines group (another branch of Natural Resources Canada), who brought displays about their research on pipeline safety.

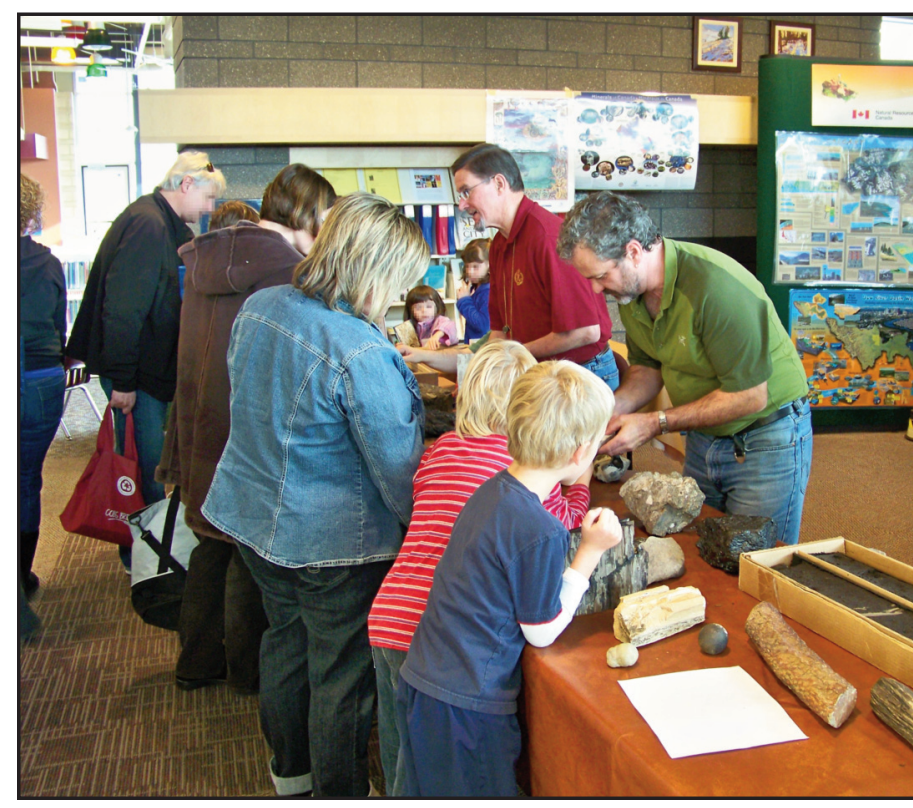

Figure 3. Holding events in high traffic, public areas of the host library branch helps to ensure that each Rock ' $n$ ' Fossil Road Show is visited by as many library patrons as possible. It also helps to ensure that the volunteers are seldom idle. Note the drill core of Athabasca oil sand at lower right in foreground, an example of an Alberta-focused display specimen.

Early Road shows were held in program rooms at the hosting library branches. These were essentially multi-purpose rooms set off from the main area of the library. While this was all right for people who already knew about the event and had come expressly to attend it, we found that being away from the main part of the library reduced our visibility and opportunities to interact with library patrons. Many program rooms had only one door or lacked natural light, which made them uninviting and problematic for people moving in and out. As a result, we now request (gently insist) that our program be held in a public area of the library with as much natural light as possible. We have found the library branches to be very willing to let us operate in this way, and some staffers have happily commented that events like ours show that their branch is actively serving the community. The result has been a more pleasant working environment for us and, we think, more interactions with the public (Fig. 3).

\section{SIGNS OF SUCCESS}

Since the key goal of the Rock 'n' Fossil Road Show is to increase public awareness of the earth sciences, the number of interactions with members of the public is an important outward measure of our success. Although we did not track the number of visitors to our first four events, we have since tried to estimate attendance (Table 1). Based on our estimates, we have interacted with more than 3700 individuals, of all ages, since we began tracking. Unsurprisingly, our largest turn-outs have been at larger library branches, which tend to have more patrons than smaller, neighbourhood branches. Our record turnout is 500 people, which has happened twice, both times at the Crowfoot Library, which is the largest branch in Calgary's NW quadrant. Our smallest turnouts have been roughly 
Table 1. Dates and locations of Rock ' $n$ ' Fossil Road shows with the estimated attendance for events from autumn, 2006, onward.

\begin{tabular}{llc}
\hline \hline DATE & LIBRARY BRANCH & ATTENDANCE \\
\hline $2004-10-23$ & Crowfoot & not recorded \\
not recorded \\
not recorded \\
$2005-10-15$ & Shawnessy & not recorded \\
$2006-04-01$ & Signal Hill & 100 \\
$2006-10-14$ & Village Square & $250-300$ \\
$2007-03-31$ & Fish Creek & $350-400$ \\
$2007-10-13$ & Country Hills & $100-125$ \\
$2008-04-05$ & Forest Lawn & $400-500$ \\
$2008-10-18$ & Crowfoot & $350-400$ \\
$2009-04-04$ & Fish Creek & $250-300$ \\
$2009-10-17$ & Nose Hill & $300-350$ \\
$2010-10-23$ & Country Hills & $300-350$ \\
$2011-10-22$ & Signal Hill & 250 \\
$2012-10-20$ & Saddletowne & 250 \\
$2013-10-19$ & Bowness & 250 \\
$2014-10-18$ & Thornhill & 200 \\
$2015-10-17$ & Alexander Calhoun & $450-500$ \\
$2016-10-15$ & Crowfoot & \\
\hline
\end{tabular}

100 people, which happened twice at smaller libraries where, for reasons that were unclear, there was little interest in the event. As a rule, even the small venues see turnouts of 200 250 people, and the attendees are just as engaged and enthusiastic as patrons of larger branches. We do think it is important to cover both the big libraries and the smaller, neighbourhood branches.

Although we do not actively survey attendees for their views of how successful we are at communicating our science, we have received consistent and strongly positive feedback from attendees and from library staff, including numerous instances of people asking where and when the next event will take place. Staff members at smaller branches have commented that hosting the Road Show meant they had a busier-thanusual Saturday, and librarians at all branches commonly express the hope that we will come back again.

It is important to comment on an inward measure of success as well. Despite the changing demographics of our group of volunteers, we have been running Rock ' $n$ ' Fossil Road shows successfully for more than a decade. This history includes two major transitions in the leadership of the event, pointing to the importance of intentional 'succession planning' for ensuring the ongoing success of outreach activities such as this.

We have reason to think that the Road Show model can be applied in a wide range of community settings. In 2015, two of us (KMF and RBM) were conducting field work based out of the small northern community of Colville Lake, NWT. During the field season, we made a point of collecting representative samples of the main types of rocks and fossils that local people might encounter on the land. On our last evening in Colville Lake, we displayed the samples on a picnic table at the community barbeque pit. The event had been promoted by the community leadership and, despite many people being away at a reunion in a neighbouring community, we had a good turnout. Some community members brought rocks that they had collected and were curious about, and many people stopped by to look at our display. Interactions ranged from watching small children use the samples as stacking blocks to hearing a community elder share her memories of traditional Dene uses of rocks. In this smaller community setting, we were able to operate a successful event with two research scientists and one summer student. Afterwards, we donated the specimens to the community for use in their school.

\section{REASONS FOR SUCCESS}

The Rock 'n' Fossil Road Show has benefited from several demographic, logistic, and pedagogic advantages. Public interest in the events may reflect the prominent place of energy resources in the Alberta economy, and the resultant large number of geoscientists living in Calgary. GSC-Calgary is well positioned to run this kind of event, being blessed with a critical mass of keen scientists, technicians, and students who are encouraged by local management that has consistently recognized the value of public outreach. Our long-standing partnership with Alberta Science Network is important for ensuring publicity and also gives us credibility with library staff, who are more likely to be aware of ASN than of GSC. Partnership with the Alberta Palaeontological Society has helped to ensure that we have sufficient volunteers present for each Road Show, while also adding to the diversity of our displays.

By providing a venue for the Road Show, the branches of the CPL play an obvious role in ensuring success. Most branches have responded enthusiastically when approached about hosting an event. Holding the Road Show in libraries lets us take science into the community in a location already associated both with learning and enjoyment. For some events, library staff has set up a display of earth science books from the branch's collection, so that interested patrons can follow up by reading about minerals, rocks, or fossils. Using libraries as venues lets us engage with passers-by as well as dedicated rock and fossil collectors, and also lets us visit different parts of the city from year to year, giving us an ever changing 'market'-a market now into its second generation of new attendees.

A key pedagogical advantage derives from the excellent outreach collection of high-quality mineral, rock, and fossil specimens to which we have access at GSC-Calgary. These are the backbone of our Road Show displays and include Albertafocused materials such as ammolite (gem-quality ammonite shell) or drill core from the Athabasca oil sands (Fig. 3). In a discussion of best practices in urban earth-science outreach, Harnick and Ross (2004, p. 426) identified access to authentic materials as a key element for success, noting that " $\mathrm{h}]$ ands-on experiences with real fossils can engage students . . . by drawing upon their interests and by entrusting them to handle materials of scientific and cultural value. In addition, a hands-on approach provides opportunities for students of different learning styles, including those with limited English proficiency, to actively engage in scientific processes and content." The 
Alberta third grade curriculum includes a major unit on rocks and minerals, meaning that many of the young people who visit our events have already been introduced to basic principles of geology, and our events help reinforce what they already know. (It is especially gratifying to watch knowledgeable children explaining our specimens to their parents and grandparents.)

The Rock 'n' Fossil Road Show shares an advantage with the original Pet Rock and Fossil Clinic. As Nowlan and Neale (2000, p. 26) noted in their discussion of that initiative, "[t]he strength of this type of event is that the scientific discussion is based on an object of considerable mutual interest." The fact that the items under discussion may have been collected by the visitor, or perhaps have a strong family connection, contributes to this. Harnick and Ross (2004) similarly noted that when urban outreach efforts were focused on specimens that students had collected personally, or that came from the local neighbourhood, it led to students displaying increased investment and interest during learning activities. "Incorporating local examples into classroom activities increases student confidence as it draws upon student experiences and background knowledge while demonstrating the connection between classroom curricula and student experience" (Harnick and Ross 2004, p. 426).

The Rock 'n' Fossil Road Show originated in an effort to develop an earth science variant on the pop culture phenomenon of the long-running Antiques Roadshow. This was reflected in the format of the first event, which focused on identifying specimens brought in by members of the public and filming interactions between earth scientists and the public for broadcast. However, the Rock 'n' Fossil Road Show quickly developed in directions distinct from its inspiration. A key difference is that from the beginning we have emphasized the scientific stories told by specimens and downplayed their commercial value. We lack the expertise to pronounce on such matters, and we also have found that commercial value is of interest only to a minority of attendees at our events. This is in contrast to the Antiques Roadshow, where the value of the antiques is a strong driver for attendance (Bishop 2001) and arguably the biggest focus of the resulting broadcasts (Clouse 2008).

The Road Show and its inspiration also are radically different in scale. A single Antiques Roadshow event in the United States will be attended by 6,000 people, who will wait through a complex series of pre-assessments, with many of the attendees never actually having their antiques looked at by a specialist (Bishop 2001; Hix 2014). Our process is much more straightforward. Anyone can walk up to the display tables and be sure that their specimens will be 'appraised' by experts (Fig. 3). This includes even the 'mystery' specimens that we cannot identify. One segment of the original TV episode included a scientist offering multiple hypotheses for the origin of an odd structure in a rock, and then concluding that it was not possible to make a confident interpretation. It seems unlikely that an antique that could not be definitively appraised would ever make it to camera on the Antiques Roadshow.

Over time, the Rock 'n' Fossil Road Show has evolved to focus on the display and explanation of GSC specimens, although the opportunity to have specimens identified is still strongly promoted and people still bring in their rocks and fossils. For those who do, we suspect that the strongest driver is the same one that Bishop (2001, p. 199) identified in an ethnographic study of the Antiques Roadshow (at a 1999 filming of the program in Baltimore): "For many of the attendees, curiosityabout their items and the items brought by others-was the primary motivation for coming ..." We suspect that curiosity also is the main reason that casual passers-by stop to take in the displays at the Rock 'n' Fossil Road Show.

There may be additional reasons for attending the event. Some attendees appear to be seeking validation regarding the interest value of their specimens, or may even have a desire to show them off. Other attendees already are sure of the identity of their samples but want to 'stump the experts' at the event. Such interactions are uncommon but, when done with mutual good humour, can be enjoyable. It also is fun and educational for the public to see specialists scratching their heads and conferring with each other while struggling to identify a specimen. Some of the more bemusing interactions at Road Shows have involved a whale's ear bone, small children and their gravel collections, or people with collections of polished pebbles, colourized agates, or 'mystical' crystals.

\section{CONCLUSIONS}

The Rock 'n' Fossil Road Show grew out of GSC-Calgary's earlier educational outreach efforts, especially the Pet Rock and Fossil clinics of the 1990s. Beginning with a 'one-off' outreach opportunity inspired by the pop culture phenomenon of the Antiques Roadshow, it has evolved into GSC-Calgary's major annual science outreach event. Our collaboration with the Calgary Public Library system has given us access to numerous venues, although similar events could be held in shopping malls, sports facilities, community halls, or museums. Our experience suggests that the Road Show model is a good educational outreach option for any earth-science research institute with a critical mass of knowledgeable volunteers and access to a collection of specimens that have scientific interest and visual impact. This approach also lends itself to modification as circumstances demand. After more than a decade, we believe that the most important reason for the success of the Rock ' $n$ ' Fossil Road Show is its focus on taking science to the public, via events that are both engaging and informative.

\section{ACKNOWLEDGEMENTS}

The authors of this article have all been organizers of the Rock 'n' Fossil Road Show at various times. We thank the volunteers who have contributed to the success of these events, and we acknowledge the contributions of various persons affiliated with the Calgary Science Network, Alberta Science Network, Alberta Palaeontological Society, Calgary Public Library, and the Natural Resources Canada communications branch. All photographs were kindly provided by Karla Williamson (Alberta Science Network), who also authorized us to use her son's visage in Figure 1. We thank Rod Smith for comments that improved the focus and clarity of an earlier version of the manuscript, and John Calder for his encouraging review on behalf of the journal. This is NRCan contribution 20170044.

\section{REFERENCES}

Bishop, R., 2001, Dreams in the line: A day at the Antiques Roadshow: The Journal of Popular Culture, v. 35, p. 195-209, https://doi.org/10.1111/j.0022-3840.2001. 3501_195.x

Clouse, A., 2008, Narratives of value and the Antiques Roadshow: "A game of recog- 
nitions": The Journal of Popular Culture, v. 41, p. 3-20, https://doi.org/ 10.1111/j.1540-5931.2008.00489.x.

Harnick, P.G., and Ross, R.M., 2004, Models of inquiry-based science outreach to urban schools: Journal of Geoscience Education, v. 52, p. 420-428, https://doi.org/10.5408/1089-9995-52.5.420.

Hix, L., 2014, The waiting game: What it really takes to get on Antiques Roadshow: Collectors Weekly, Available at: http://www.collectorsweekly.com/articles/ what-it-really-takes-to-get-on-antiques-roadshow/, (Accessed December 12, 2016).

Nowlan, G.S., and Neale, E.R.W., 2000, Evolution of the Calgary Science Network: an unabashed tale of speciation, extinction, and diversity: Geoscience Canada, v. 27, p. 23-30.

Poulton, T., Neumar, T., Osborn, G., Edwards, D., and Wozniak, P., 2002, Geoscape Calgary: Geological Survey of Canada, Miscellaneous Report 72, 1 sheet, https://doi.org/10.4095/213244.

Turner, R.J.W., 2013, Geoscape: Lessons learned from 15 years of geoscience outreach: Geoscience Canada, v. 40, p. 371-381, https://doi.org/10.12789/geocanj.2013.40.30.

Received January 2017

Accepted as revised May 2017

\section{GEOLOGICAL ASSOCIATION OF CANADA}

$$
\text { (2016-2017) }
$$

\section{OfFICERS \& COUNCILloRs}

\section{OFFICERS}

President

Graham Young

Vice-President

Stephen Morison

Past President

Victoria Yehl

Secretary-Treasurer

James Conliffe

Alwynne Beaudoin

\section{COUNCILLORS}

Ihsan Al-Aasm

Oliver Bonham

James Conliffe

Louise Corriveau

Andy Kerr

Stephen Morison

David Pattison

Sally Pehrsson

Liz Stock

Dène Tarkyth

Chris White

Victoria Yehl

Graham Young

\section{STANDING COMMITTEES}

Communications: Sally Pehrsson

Finance: Dène Tarkyth

GAC Lecture Tours: Alwynne Beaudoin

Publications: Chris White

Science Program: Louise Corriveau 